\title{
Hubungan Antara Usia dan Masa Kerja dengan Kelelahan Kerja pada Pekerja Industri Rumah Tangga Peleburan Alumunium di Desa Eretan Kulon Kabupaten Indramayu
}

\author{
The Relationship Between Age and Employment With Work Fatigue in Domestic Industri \\ Alumunium Smelting Eretan Indramayu
}

\section{Nabila Nala Utami ${ }^{1}$, H. Riyanto ${ }^{2}$, H. Aman Evendi ${ }^{3}$}

${ }^{1,2,3}$ Program Studi Kesehatan Masyarakat Universitas Wiralodra

\begin{abstract}
Abstrak
Kelelahan mengarah pada kondisi melemahnya tenaga kerja untuk melakukan kegiatan. Peleburan alumunium adalah pekerja melakukan peleburan alumunium dari bahan bubutan/lelean untuk membuat pelek mobil, motor, dan lainlain. Setiap pekerjaan yang berisiko akan menimbulkan kelelahan. Beberapa pekerja peleburan alumunium mengeluhkan gejala kelelahan seperti kurang percaya diri, susah berkonestrasi, lelah seluruh tubuh, lelah berbicara karena selama 24 jam dengan 10 jam kerja perhari. Tujuan penelitian ini untuk mengetahui gambaran dan hubungan antara usia, masa kerja dengan kelelahan kerja pada pekerja industry peleburan alumunium Eretan Kulon Indramayu tahun 2018. Jenis penelitian ini yang digunakan adalah observasional analitik dengan metode cross sectional. Populasi dalam penelitian ini sebanyak 30 pekerja dan sampel dalam penelitian ini menggunakan total sampling dimana semua populasi dijadikan sampel penelitian. Instrumen pada penelitian ini menggunakan IFRC. Dari 30 pekerja industry peleburan alumunium yang dijadikan sampel sebanyak 23 pekerja $(76,7 \%)$ mengalami kelelahan berat dan 7 pekerja $(23,3 \%)$ mengalami kelelahan ringan. Pengujian data menggunakan uji statistic Chi Square. Hasil penelitian menunjukan bahwa terdapat hubungan yang bermakna antara usia denga kelelahan $(p=0,033)$, masa kerja dengan kelelahan $(p=0,016)$. Disarankan pekerja dapat memanfaatkan waktu istirahat seoptimal mungkin,
\end{abstract}

Kata Kunci : Usia, Masa Kerja, Kelelahan Kerja

\section{Abstract}

Fatigue leads on condition weaking of labor to do activities. Alumunium smelting it is work who do alumunium smelting from material bubutan or lelean to make a car rim, motor and others. Any work at risk will cause fatigue. Som,e alumunium smelting workers complaining symptoms of fatigue such as lack of confidence, difficult to concentrate, tired whole body, tired of talking, because for 24 hours with 10 working hours per day. The purpose of this study is to understand the picture and the relationship between working age and work fatigue in alumunium smelting industry workers eretan kulon indramayu tahun 2018. This type of research is in use is observasional methods cross sectional. The population in this study were 30 workers and the sample in this study using total sampling where all the population in the of research. Instrument in this study using IFRC. Of the 30 alumunium smelting workers in the sample were 23 workers (76,7\%) experienced fatigue berst and 7 workers $(23,3 \%)$ have mild tiredness. Testing data using test statistic Chi Square. The results showed that there was a significant relationship between age and fatigue $(p=0,033)$. Working period with fatigue $(p=0,016)$. It is recommended that workers can make the most of their rest time

\section{Keywords Working: Age, Employment, Fatigue}

\section{Pendahuluan}

Indonesia merupakan Negara yang berkembang dan sangat membutuhkan sumber daya manusia seperti tenaga kerja yang sehat, efisien dan produktif. Tenaga kerja seperti ini di harapkan akan mampu berkompetisi dengan tenaga kerja yang lain. Baik di dalam dan di luar negrti. Keunggulan tersebut dapat tercapai bila semua pihak turut berperan aktif bekerja sama dengan tingkat kemampuan yang ada pada tenaga kerja itu sendiri. Undang-undang RI No. 13 Tahun 2003 tenaga kerjaan pasal 68 ayat 1 menyatakan bahwa setiap pekerja atau buruh mempunyai hak untuk memperoleh perlindungan atas keselamatan dan kesehatan kerja, moral dan kesusilaan dan perlakuan yang sesuai dengan harkat dan martabat manusia serta nilai-nilai agama ${ }^{1}$. 
Kelelahan kerja didefinisikan sebagai suatu kondisi yang timbul pada setiap individu yang telah tidak sanggup lagi untuk melakukan aktivitasnya $^{2}$. Istilah kelelahan mengarah pada kondisi melemahnya tenaga untuk melakukan suatu kegiatan, walaupun ini bukan satusatunya gejala ${ }^{3}$. Kelelahan kerja merupakan bagian dari permasalahan umum yang sering dijumpai pada tenaga kerja. Menurut beberapa peneliti, kelelahan secara nyata dapat mempengaruhi kesehatan tenaga kerja dan dapat menurunkan produktivitas 4 .

Industri rumah tangga peleburan alumunium ini merupakan proses pembuatan batang alumunium untung membuat pelek mobil, motor, peralatan rumah tangga, dan lain-lain. memiliki bagian pekerjaan yaitu persiapan bahan, pemilihan bahan, pengolahan, pencetakan, pelepasan dari cetakan dan pengepakan, alumunium berbahan dasar dari bubutan atau lelean. Industry peleburan alumunium yang berada di jalan Kali Anyar di desa Eretan Kulon Indramayu.

Berdasarkan survei awal peneliti yang dilakukan pada pekerja industri rumah tangga peleburan alumunium Eretan Kulon Indramayu, terdapat sebanyak30 pekerja dengan mayoritas berjenis kelamin laki-laki. Pekerjaan mereka yang dilakukan cukup berisiko karena melakukan proses peleburan bahan bubutan. Setiap pekerjaan berisiko menimbulkan kelelahan dari faktor usia yang bertambah tua dan masa kerja yang lama akan mempercepat seseorang merasa lelah. Hasil pengisian kuesioner yang dilakukan pada pekerja industri peleburan alumunium, beberapa diantaranya mengeluhkan gejala kelelahan secara subyektif yaitu kurang berkonsentrasi, lelah seluruh tubuh karena bekerja selama 24 jam dengan 10 jam kerja perhari, lelah berbicara, susah berfikir, kurang percya diri, dan cenderung lupa.

\section{Metode Penelitian}

Jenis penelitian ini adalah Survey Analitik, dengan menggunakan pendekatan Cross
Sectional. Lokasi dilakukan penelitian ini adalah pekerja Industry Peleburan Alumunium Eretan Kulon Indramayu, yang dilaksanakan pada bulan Januari 2018. Populasi dalam penelitian ini adalah pekerja peleburan alumunium yaitu sejumlah 30 pekerja. Sedangkan sampel dalam penelitian ini menggunakan teknik total sampling dimana semua populasi dijadikan sebagai sample penelitian, sebanyak 30 pekerja. Data yang digunakan ialaha data primer dan data sekunder. Data primer diperoleh dari kuesioner IFRC. Sementara data sekunder dalam penelitian ini adalah profil desa dan profil industry rumah tangga peleburan alumunium. Analisis data yang digunakan adalah analisis bivariat dan analisis univariat. Analisis univariat digunakan dengan tujuan untuk mengetahui gambaran pekerja industry rumah tangga peleburan alumunium Eretan Kulon Indramayu yang meliputi usia dan masa kerja. Sedangkan analisis bivariat dilakukan dengan uji statistic Chi Square menggunakan program SPSS versi16.0 untuk mengtahui hubungan antara variabel-variabel tersebut.

\section{Hasil}

\section{Analisis Uivariat Gambaran Usia}

Tabel 1. Distribusi Frekuensi Usia pada Pekerja Industri Rumah Tangga Peleburan Alumunium

\begin{tabular}{cccc}
\hline No & Usia & Frekuensi & $\mathbf{\%}$ \\
\hline 1 & Dewasa awal & 7 & 23,3 \\
2 & Dewasa akhir & 23 & 76,7 \\
& Total & 30 & 100 \\
\hline
\end{tabular}

Berdasarkan tabel 1 diatas dapat diketahui pekerja industry peleburan alumunium dengan usia dewasa awal sebanyak 16 pekerja $(23,3 \%)$ dan dewasa akhir sebanyak 20 pekerja $(7,6 \%)$. 


\section{Gambaran Masa Kerja}

Tabel 2. Distribusi Frekuensi Masa Kerja pada Pekerja Industri Rumah Tangga Peleburan Alumunium

\begin{tabular}{clcc}
\hline No & Masa Kerja & Frekuensi & \% \\
\hline 1 & Baru & 6 & 20,0 \\
2 & Lama & 24 & 80,0 \\
& Total & 30 & 100 \\
\hline \multicolumn{4}{c}{ Sumber: } \\
\multicolumn{4}{c}{ Data Primer Tahun } \\
& & 2018
\end{tabular}

Berdasarkan tabel 2. diatas dapat diketahui pekerja industri peleburan alumunium dengan masa kerja baru sebanyak 6 pekerja $(20,0 \%)$ dan masa kerja lama sebanyak 24 pekerja $(80,0 \%)$.

\section{Gambaran Kelelahan kerja}

Tabel 2. Distribusi Frekuensi Kelelahan Kerja pada Pekerja Industri Rumah Tangga

Peleburan Alumunium

\begin{tabular}{cccc}
\hline No & $\begin{array}{c}\text { Kelelahan } \\
\text { Kerja }\end{array}$ & Frekuensi & $\mathbf{\%}$ \\
\hline 1 & Rendah & 6 & 20,0 \\
2 & Tinggi & 24 & 80,0 \\
& Total & 30 & 100 \\
\hline
\end{tabular}

Berdasarkan tabel 3. Diatas dapat diketahui pekerja industri peleburan alumunium dengan kelelahan rendah sebanyak 7 pekerja $(23,3 \%)$ dan kelelahan tinggi sebanyak 23 pekerja $(76,7 \%)$.

\section{Analisis Bivariat}

Adapun hasil dari analisisi bivariat pada penelitian ini, dimana melihat hubungan antar variabel dependen dan variabel independen. Hasil analisis bivariate melihat hubungan antara usia dan masa kerja terhadap kelelahan kerja yang disajikan dalam tabel 4 dan 5 sebagai berikut:

Tabel 4. Hubungan antara Usia dengan Kelelahan Kerja pada Pekerja Industri Rumah Tangga Peleburan Alumunium

\begin{tabular}{|c|c|c|c|c|c|c|c|c|c|}
\hline \multirow[t]{2}{*}{ No } & \multirow[b]{2}{*}{ Usia } & \multicolumn{2}{|c|}{ Kelelahan } & \multirow[t]{2}{*}{ Jumlah } & \multirow[t]{2}{*}{ p-value } & \multirow[t]{2}{*}{$\mathrm{SC}$} & \multirow[t]{2}{*}{ RR } & \multicolumn{2}{|c|}{$95 \% \mathrm{CI}$} \\
\hline & & Rendah & Tinggi & & & & & Lower & Upper \\
\hline \multirow[t]{2}{*}{1.} & Dewasa Awal & 4 & 2 & 7 & & & & & \\
\hline & & $13,3 \%$ & $6,7 \%$ & $23,3 \%$ & & & & & \\
\hline \multirow[t]{4}{*}{2.} & Dewasa Akhir & 3 & 21 & 23 & 0,033 & 0,4 & 0,4 & 0,206 & 1,176 \\
\hline & & $10,0 \%$ & $70,0 \%$ & $76,7 \%$ & & 41 & 93 & & \\
\hline & Jumlah & 7 & 23 & 30 & & & & & \\
\hline & & $23,3 \%$ & $76,7 \%$ & $100 \%$ & & & & & \\
\hline
\end{tabular}

Sumber: Data Primer Tahun 2018

Berdasarkan tabel 4. Dari 30 pekerja peleburan alumunium, terdapat 4 pekerja $(13,3 \%)$ orang termasuk dalam kategori rendah dan kategori tinggi $2(6,7 \%)$ orang dewasa awal dan terdapat $3(10,0 \%)$ pekerja dalam kategori rendah dan kategori tinggi $21(70,0 \%)$ orang. Hasil uji Chi Square diperoleh nilai Ekspetasi $<5$ sehingga digunakan nilai Fhisher's Exact Test sebagai p-value yaitu sebesar $0,033(p<0,05)$ yang berarti hubungan yang bermakna antara usia dengan kelelahan kerja pada pekerja Peleburan Alumunium Eretan Tahun 2018. 
Tabel 5. Hubungan antara Masa Kerja dengan Kelelahan Kerja pada Pekerja Industri Rumah Tangga Peleburan Alumunium

\begin{tabular}{|c|c|c|c|c|c|c|c|c|c|}
\hline \multirow[t]{2}{*}{ No } & \multirow[b]{2}{*}{ Masa Kerja } & \multicolumn{2}{|c|}{ Kelelahan } & \multirow[t]{2}{*}{ Jumlah } & \multirow[t]{2}{*}{$p$-value } & \multirow[t]{2}{*}{$\mathrm{SC}$} & \multirow[t]{2}{*}{$\mathrm{RR}$} & \multicolumn{2}{|c|}{$95 \% \mathrm{CI}$} \\
\hline & & Rendah & Tinggi & & & & & Lower & Upper \\
\hline \multirow[t]{2}{*}{1.} & Baru & 4 & 2 & 6 & & & & & \\
\hline & & $13,3 \%$ & $6,7 \%$ & $20,0 \%$ & & & & & \\
\hline \multirow[t]{4}{*}{2.} & Lama & 1 & 21 & 24 & 0.016 & 0,512 & 0,381 & 0,122 & 1,193 \\
\hline & & $3,3 \%$ & $70,0 \%$ & $80,0 \%$ & & & & & \\
\hline & Jumlah & 4 & 26 & 30 & & & & & \\
\hline & & $13,3 \%$ & $86 \%$ & $100 \%$ & & & & & \\
\hline
\end{tabular}

Berdasarkan tabel 5. Dari 30 pekerja peleburan alumunium, terdapat 4 pekerja $(13,3 \%)$ orang termasuk dalam kategori rendah dan kategori tinggi 2 pekerja $(6,7 \%)$ orang. Terdapat 1 pekerja $(3,3 \%)$ orang dalam kategori rendah dan kategori tinggi 21 pekerja (70,0\%) orang. Hasil uji Chi Square diperoleh nilai Ekspetasi $<5$ sehingga digunakan nilai Fhisher's Exact Test sebagai $p$-value yaitu sebesar 0,016 (p $<0,05)$ yang berarti hubungan yang bermakna antara masa kerja dengan kelelahan kerja pada pekerja Peleburan Alumunium Eretan Tahun 2018.

\section{Pembahasan}

\section{Usia dengan Kelelahan Kerja pada Pekerja Peleburan Alumunium}

Berdasarkan hasil penelitian pada tabel 5.4 dengan menggunakan uji Chi Square diperoleh nilai Ekspetasi $<5$ sehingga digunakan nilai fisher's exact test sebagai $p$-value yaitu sebesar 0,033 ( $p$-value < $0,05)$ berarti Ho ditolak, artinya ada hubungan antara usia dengan kelelahan kerja pada pekerja industry rumah tangga peleburan alumunium di desa Eretan Kulon Indramayu Tahun 2018. Hal ini sejalan dengan penelitian Medianto (2017), yaitu ada hubungan antara usia dengan kelelahan kerja pada Tenaga Kerja Bongkar Muat bagian pemanggul pupuk dipelabuhan tanjung emas Semarang dengan $p$-value 0,025 ( $p$-value $<0,05)$.

Untuk mengetahui tingkat kekuatan hubungan dapat dilihat dari nilai Spearman Correlation (SC), dari dua variabel yaitu usia pekerja dengan kelelahan berdasarkan hasil perhitungan dengan uji statistic Spearman Correlation dengan menggunakan SPSS versi 16.0 menunjukan hubungan cukup kuat antara usia pekerja dengan kelelahan kerja yaitu dengan nilai $\mathrm{SC}=0,441$ atau $44,1 \%$ dengan demikian dapat disimpulkan bahwa terdapat hubungan cukup kuat antara usia pekerja dengan kelelahan kerja.

Karena usia seseorang akan mempengaruhi kondisi tubuhnya, seseorang yang berusia muda akan sanggup melakukan pekerjaan berat dan sebaliknya jika seseorang berusia lanjut maka kemampuan untuk melakukan pekerjaan berat akan menurun, pekerja yang telah berusia lanjut akan merasa cepat lelah dan tidak bergerak tidak gesit ketika melaksanakan tugasnya sehingga mempengaruhi kinerjanya ${ }^{5}$.

\section{Masa Kerja dengan Kelelahan Kerja pada Pekerja Peleburan Alumunium}

Berdasarkan hasil penelitian pada tabel 5.5 menggunakan uji Chi Square diperoleh nilai Ekspetasi $<5$ sehingga digunakan nilai Fisher's Exact Test 
sebagai $p$-value yaitu sebesar 0,016 ( $p$ value $<0,05)$ maka Ho ditolak, artinya ada hubungan antara masa kerja dengan kelelahan kerja pada pekerja peleburan alumunium.

Untuk mengetahui tingkat kekuatan hubungan dapat dilihat dari nilai Spearman Correlation (SC), dari dua variabel yaitu masa kerja dengan kelelahan kerja pada pekerja peleburan alumunium, berdasarkan hasil perhitungan dengan uji statistik Spearman Correlation dengan menggunakan SPSS versi 16.0 menunjukan hubungan kuat antara masa kerja dengan kelelahan kerja pada pekerja peleburan alumunium yaitu dengan nilai $\mathrm{SC}=0,512$ atau $51,2 \%$ sehingga dengan demikian dapat disimpulkan bahwa terdapat hubungan kuat antara masa kerja dengan kelelahan pada pekerja peleburan alumunium

Masa kerja akan memberikan pengaruh positif bila semakin lama seseorang bekerja akan berpengalaman dalam melakukan pekerjaannya. Sebaliknya akan memberikan pengaruh negatif apabila semakin lama bekerja akan menimbulkan kelelahan, kebosanan dan semakin banyak terpapar bahaya yang ditimbulkan oleh lingkungan $\operatorname{kerja}^{6}$ Penelitian ini sejalan dengan penelitian Vilda (2014), dengan $p$ value $=0,028$ yang berarti terdapat hubungan antara masa kerja dengan kelelahan kerja pada karyawan Perusahaan Tahu Baxo Bu Pudji di Ungaran ${ }^{7}$.

\section{Kesimpulan}

1. Terdapat hubungan yang bermakna antara usia dengan kelelahan kerja dengan $p$-value 0,033 ( $p$-value $<0,05$ ).

2. Terdapat hubungan yang bermakna antara masa kerja dengan kelelaha kerja dengan $p$-value 0,016 ( $p$-value < $0,05)$.
3. Terdapat hubungan cukup kuat dengan nilai Spearman Correlation $(\mathrm{SC})=$ 0,441 atau $44,1 \%$ antara usia dengan kelelahan kerja pada pekerja peleburan alumunium di desa Eretan Kulon Indramayu Tahun 2018

4. Terdapat hubungan kuat dengan nilai Spearman Correlation $(\mathrm{SC})=0,512$ atau 51,2\% antara masa kerja dengan kelelahan kerja pada pekerja peleburan alumunium di desa Eretan Kulon Indramayu Tahun 2018

\section{Saran}

Perlu ada pengaturan beban kerja dan memanfaatkan waktu istirahat seoptimal mungkin agar kelelahan kerja yang dirasakan bisa berkurang

\section{Daftar Pustaka}

1. Undang-Undang Republik Indonesia Nomor 13 Tahun 2003 Tentang Ketenagakerjaan.

2. Soedirman, dan Suma'mur. P.K., 2014. Kesehatan Kerja Dalam Perspektif Hiperkes Dan Keselamatan Kerja. Jakarta, Penerbit Erlangga.

3. Budiono, dkk. 2003. Kelelahan (Fatigue) pada tenaga kerja bunga rampai hiperkes dan keselataman kerja. Semarang; Universitas Diponegoro.

4. Januar Atiqoh Ida Wahyuni, Daru Lestantyo. 2014 Faktor-faktor yang Berhubungan dengan Kelelahan Kerja pada Pekerja Konveksi Bagian Penjahitan di CV.Aneka Garment Gunungpati Semarang. Jurnal Kesehatan Masyarakat (e-Journal), Volume 2, Nomor 2,Pebruari 2014. Online d ihttp://ejournals1.undip.ac.id/index.php/jkm 
5. Suma'mur P.K, 1982. Ergonomi Untuk Produktivita Kerja. IKIP. Yogyakarta.

6. Setyawati, 2011. Selintas tentang kelelahan kerja. Yogyakarta; amara books.

7. Diana Puspita Langgar, Vilda Ana Veria Setyawati. 2014. Hubungan antara Asupan Gizi dan Status Gizi dengan Kelelahan Kerja Pada Karyawan Perusahaan Tahu Baxo Bu Pudji Di Ungaran Tahun 2014. Jurnal Kesehatan Masyarakat Visikes. Vol 13, No 2 (2014) 